\title{
Afro do Amaral Fontoura: a sistematização de saberes aritméticos para os cursos de formação de professores da Guanabara (1960-1974)
}

\author{
Afro do Amaral Fontoura: the systematization of arithmetic knowledge for \\ the Guanabara teacher training courses
}

Afro do Amaral Fontoura: la sistematización del conocimiento aritmético para los cursos de formación de profesores de Guanabara

\author{
Denise Medina de Almeida França \\ Universidade do Estado do Rio de Janeiro (Brasil) \\ https://orcid.org/0000-0002-1649-5816 \\ http://lattes.cnpq.br/4540272100520547 \\ denisemedinafranca@gmail.com
}

\begin{abstract}
Resumo
$\mathrm{O}$ artigo investiga se o professor Afro do Amaral Fontoura pode ser considerado um expert da matemática escolar em tempos de Escola Nova, bem como os saberes por ele sistematizados no Programa do ensino primário do estado da Guanabara, publicado em 1962. O referencial teórico metodológico utiliza os seguintes conceitos: saberes profissionais, matemática para ensinar, matemática $a$ ensinar e expert. O estudo é norteado pelas questões a seguir: que vestígios nos possibilitam afirmar que Afro do Amaral Fontoura foi um expert para o curso de formação de professores no ensino da matemática, no período de 1950 a 1970, nas séries iniciais, ao propor ideias escolanovistas? Que saberes foram sistematizados e objetivados por Fontoura por meio do Programa de Aritmética do Estado da Guanabara (1961)? Buscando responder a essas indagações, com base em fontes encontradas no Instituto Superior de Educação do Rio de Janeiro, verificamos que Fontoura se enquadra na categoria de expert da educação no Estado da Guanabara, de modo que possibilitou a sistematização de saberes aritméticos abordados por meio de situações da vida prática.
\end{abstract}

Palavras-chave: Expert. Sistematização de saberes. Afro do Amaral Fontoura. 


\begin{abstract}
The article investigates whether the teacher Afro do Amaral Fontoura can be considered an expert in school mathematics in times of Escola Nova and also investigates the knowledge he systematized in the primary education program of the state of Guanabara, published in 1962. The methodological theoretical framework uses the following concepts: professional knowledge, mathematics to teach, mathematics for teaching and the expert. The study is guided by the following questions: what traces allow us to affirm that Afro do Amaral Fontoura was an expert for the teacher training course in the teaching of mathematics, from 1950 to 1970, in the initial grades, when proposing Escolovan ideas? What knowledge was systematized and objectified by Fontoura throughout the Arithmetic Program of the State of Guanabara (1962)? Seeking to answer these questions, based on sources found at the Higher Institute of Education in Rio de Janeiro, we found that Fontoura falls into the category of educational expert in the state of Guanabara, so that it enabled the systematization of arithmetic knowledge approached throughout practical life situations.
\end{abstract}

Keywords: Expert. Systematization of knowledge. Afro do Amaral Fontoura.

\title{
Resumen
}

El artículo investiga si el profesor Afro do Amaral Fontoura puede considerarse un experto en matemáticas escolares en tiempos de Escola Nova y el conocimiento que sistematizó en el programa de educación primaria del estado de Guanabara, publicado en 1962. El marco teórico metodológico utiliza lo siguiente conceptos: conocimiento profesional, matemáticas para enseñar, matemáticas a enseñar y expert. El estudio se guía por las siguientes preguntas: ¿qué huellas nos permiten afirmar que Afro do Amaral Fontoura fue un experto en el curso de formación docente en la enseñanza de las matemáticas, en el período de 1950 a 1970, en los grados iniciales, al proponer ideas de Escolovan? ¿Qué conocimiento fue sistematizado y objetivado por Fontoura a través del Programa Aritmético del Estado de Guanabara (1962)? Buscando responder a estas preguntas, con base en las fuentes encontradas en el Instituto Superior de Educación en Río de Janeiro, encontramos que Fontoura cae en la categoría de experto en educación en el estado de Guanabara, por lo que permitió la sistematización del conocimiento aritmético abordado a través de situaciones prácticas de la vida.

Palabras clave: Expert. Sistematización del conocimiento. Afro do Amaral Fontoura. 


\section{Introdução}

Este artigo foi produzido a partir da premissa de que o estudo histórico da constituição dos saberes que envolvem a formação do profissional docente pode elucidar como foi produzida a representação dos fundamentos de referência para a docência. Nesse sentido, Valente (2017, p. 202) questiona quais saberes profissionais devem estar presentes nessa formação. Cabe destacar também a necessidade de se pensar a importância dos experts para definir, produzir e fazer circular, por meio de suas obras, cursos, etc., esses saberes. Em outras palavras, este trabalho se propõe a analisar em perspectiva histórica a constituição dos saberes envolvidos na formação de professores. Segundo Valente (2015), esses conhecimentos são considerados sob novas bases conceituais, advindos dos "saberes objetivados", isto é, daqueles que se institucionalizam ao longo do tempo, tornando-se explícitos, formalizados, transmitidos e incluídos intencionalmente na formação de professores.

Ressaltamos que, no âmbito das pesquisas interessadas em analisar a formação profissional do professor, a discussão sobre o saber ${ }^{1}$ é algo basilar, visto que interessa compreender os movimentos para a produção do saber profissional do professor que ensina matemática.

Nesse sentido, este estudo se propõe a discutir a expertise de Afro Amaral Fontoura em Educação e a produção dos saberes profissionais, ambas as questões serão tratadas como categorias que auxiliarão nas análises.

Atentando para ponderações trazidas por Hofstetter, Schneuwly, Freymond (2017), podemos considerar a expertise como uma ação do especialista em Educação que atua dentro de uma instituição. Percebida por esse âmbito, estamos falando do profissional responsável por alinhar saberes da profissão com os da disciplina. Na prática, o especialista, também denominado expert, é chamado pelo Estado para dar conta da resolução de problemas técnicos, categorizando-os a partir da apropriação das ideias de Hofstetter et al (2017). Sobre isso, são utilizados requisitos, como: reconhecimento pelos pares por sua expertise; apropriação de concepções educacionais que circularam em nível internacional; convocação pelo Estado para resolução de problemas técnicos; sistematização de saberes no âmbito educacional, bem como sua circulação.

No Rio de Janeiro, França (2016) identificou que Afro do Amaral Fontoura foi o autor do Programa de Aritmética para o Estado da Guanabara ${ }^{2}$, no ano de 1961. Acreditamos que a análise desse documento pode permitir a compreensão de mudanças daquilo que estava anteriormente estabelecido. Este processo exige o cotejamento do referido Programa com os livros de Afro, destinados a professores e alunos, entre outros atores do cenário educacional. Dito isso, objetivamos com este artigo verificar se Afro do Amaral Fontoura pode ser enquadrado na categoria de expert, e como o nosso trabalho está centrado na sistematização de saberes. Pretendemos problematizar, ainda, por meio do Programa, o papel de Fontoura na sistematização da matemática para o ensino e para a formação de professores, ou seja, o surgimento, pelas mãos de Afro, de uma nova matemática $a$ ensinar e de uma nova matemática para ensinar.

É necessário acrescentar que aliados a uma análise documental, a historiografia que vimos compondo procura compreender os movimentos de constituição histórica dos saberes profissionais docentes, saberes a ensinar e saberes para ensinar (HOFSTETTER;

\footnotetext{
${ }^{1}$ Diferenciamos conhecimento e saber. "O primeiro mais ligado à subjetividade, às experiências vividas pelo sujeito, meios implícitos da ação, do raciocínio; o segundo, fruto de sistematização, de caráter mais consensual, passível de generalização e objetivação, produto cultural institucionalizado, cujo intento é a sistematização e organização de determinados conhecimentos com o fim de propiciar a sua comunicação" (VALENTE, 2018, p. 381).

${ }^{2}$ Em 1960, com a fundação de Brasília houve a transferência da capital federal para lá e, com isso, uma nova conformação para o espaço da cidade do Rio de Janeiro, surgindo uma nova estrutura federativa: o Estado da Guanabara (FRANÇA; VILLELA, 2015).
} 
SCHNEUWLY, 2017). Porém, ao investigarmos saberes inerentes à profissão do ensino e da formação do professor que ensina matemática, mobilizamos duas hipóteses teóricas mais específicas: a matemática a ensinar e a matemática para ensinar. A primeira, referindo-se ao objeto de ensino do professor e, a segunda, ao conjunto de ferramentas que o professor deverá ter para colocar em prática a matemática a ensinar. Ambas estão em estreita articulação, mas é a última que se constitui como os saberes profissionais dos professores que ensinam matemática (BERTINI, MORAIS, VALENTE, 2017). Assim, consideramos a matemática a e para ensinar produtos de um processo científico, oriundos de pesquisa, diálogo entre grupos de pesquisa, apropriação, reflexão, criatividade e síntese teórica. Atualmente, são hipóteses/categorias que fundamentam estudos históricos que buscam descortinar as matemáticas partícipes do processo de profissionalização docente de professores que ensinam matemática.

Dessa forma, este estudo norteia-se pela seguinte questão: que vestígios nos possibilitam afirmar que Afro do Amaral Fontoura foi um expert para o curso de formação de professores no ensino da matemática, no período de 1950 a 1970, nas séries iniciais, ao propor ideias escolanovistas $^{3}$ ? Que saberes foram sistematizados e objetivados por Fontoura por meio do Programa de Aritmética do Estado da Guanabara ${ }^{4}$ ?

Maciel (2019) afirma que existem saberes que surgem com as experiências docentes, sendo sistematizados e veiculados nos manuais pedagógicos, por meio de orientações. Por esse motivo, trazemos aqui manuais de autoria de Fontoura, objetivando auxiliar na captura dos saberes sistematizados no Programa, uma vez que a ordenação e a objetivação ocorrem por níveis ou etapas, ou seja, são processos históricos.

Assim, as orientações a professores contidas nos manuais produzidos por Fontoura podem auxiliar na análise do processo de sistematização, objetivação e institucionalização de saberes utilizados no Programa do estado da Guanabara. Para isso, procurando responder às questões, utilizamos Valente (2018) quando propõe três etapas para explicar o fenômeno da cientifização de um saber, ou ainda, a objetivação de saberes. Como ressaltamos anteriormente, consideramos conhecimento como algo subjetivo e incorporado ao sujeito, e saber como algo despersonificado, inteligível a todos e, portanto, objetivado. Valente $(2018$, p. 381) denominou as etapas de estudo do processo das transformações de um conhecimento em saber como "recompilação de experiências docentes, análise comparativa dos conhecimentos dos docentes e sistematização e uso dos conhecimentos como saberes". Buscando responder à pergunta "que saberes foram objetivados por Fontoura no Programa do estado da Guanabara?", a seguir faremos um exercício metodológico de análise deste processo utilizando as etapas propostas por Valente (2018). Para o estudo em questão, consideraremos as professoras primárias da década de 1960. França e Villela (2015) afirmam que essas docentes, em grande maioria, trabalhavam em escolas estaduais, na recém-criada modalidade de três turnos, e com rodízios semanais para suprir a demanda por vagas. As professoras, nesse período, não sofriam controle pedagógico por parte do governo e usufruíam de autonomia para elaborar seus planos de aula, visto que a ênfase daquele governo era aumentar o número de vagas, e organizar e reestruturar a nova unidade federativa. Nossa hipótese se baseia na ideia de que antes da criação do estado da Guanabara, as professoras do então estado do Rio de Janeiro, que ainda não tinham elaborado seu Programa de ensino, utilizaram a "Biblioteca da Professora Primária" ${ }^{6}$, publicada pelo Ministério de Educação e Cultura no governo

\footnotetext{
${ }^{3}$ A escola deveria oferecer oportunidades para que o aluno, a partir da observação e da experimentação, pudesse elaborar seu próprio saber, "agora o ensino associava 'ver' a 'fazer”" (VIDAL, 2011, p. 498).

${ }^{4}$ O Programa do Ensino Primário do Estado da Guanabara é uma reedição de um manual didático, vol. 1, da coleção Biblioteca Didática Brasileira, de autoria de Afro do Amaral Fontoura. O programa é de 1961, contudo estamos analisando a sexta edição, de 1965, desconhecendo se houve modificações (FRANÇA, 2016, p. 218).
} 
João Goulart, como norteadora do ensino. Assim, acreditamos que essas professoras, há muito, já utilizavam as obras de Fontoura.

\section{O prestígio de Fontoura entre seus pares}

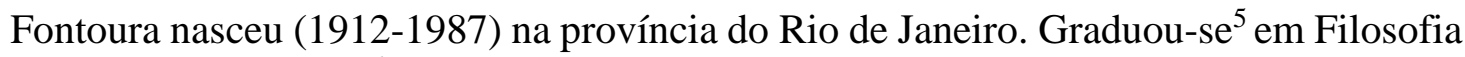
pela Universidade do Brasil ${ }^{6}$, quando a capital do país se encontrava no Rio de Janeiro, e especializou-se em Sociologia, nos Estados Unidos (FRANÇA; DOMINGUES, 2018).

Verificamos que Fontoura, sendo formado em Magistério, trabalhou como professor em várias escolas normais, iniciando na carreira docente aos 17 anos. Depois de graduado, ministrou aulas nas principais faculdades do Estado ${ }^{7}$.

Entendemos que o perfil multifacetado de Fontoura, que o permite articular saberes de vários campos, bem como estabelecer teias e conexões originadas pelas procuras e cargos ocupados, possa ter atribuído identidade a sua vida profissional. Podemos verificar atividades variadas de Fontoura consultando fontes como a Hemeroteca Digital; boa parte do noticiário vinculado à Associação Brasileira de Educação (ABE) ${ }^{8}$; O Diário de Notícias (1960) - "ABE abre as inscrições para o curso de Psicologia da Aprendizagem"; O Fluminense (1964) "Ministração de cursos 'Instituições Escolares' e 'Estudos Dirigidos' promovido pela Secretaria de Educação para professores".

Com o intuito de averiguar o processo de constituição de saberes por Fontoura, iniciamos o movimento de recompilação de experiências docentes sistematizadas, ou seja, coletamos e selecionamos informações organizadas em manuais, livros, etc., que pudessem evidenciar as propostas de trabalho pedagógico dos professores.

A recompilação de experiências docentes, do modo como estamos entendendo tal procedimento, envolve a seleção e separação de informações relatadas em revistas pedagógicas; organizadas em livros didáticos e manuais pedagógicos; normatizadas em leis do ensino; contidas em documentação pessoal de alunos e professores; materializadas em dispositivos pedagógicos para o ensino, dentre outros tipos de documentação passíveis de evidenciar informações sobre o trabalho pedagógico dos professores (VALENTE, 2019, p.380).

\footnotetext{
${ }^{5}$ Apesar de muita pesquisa, não encontramos a data de sua graduação. Sabemos que foi para a Universidade após ter concluído o curso normal. Em pesquisa na Hemeroteca encontramos sua atuação em universidades a partir de 1950. Provavelmente, concluiu a graduação em Filosofia em meados da década de 1940.

${ }^{6}$ A Universidade do Brasil, localizada no Rio de Janeiro (Distrito Federal), foi criada pela Lei ${ }^{\circ} 452$, de 5 de julho de 1937, na qual foram reunidas escolas ou faculdades, institutos e o Museu Nacional. Posteriormente, com a Reforma Universitária de 1968, transformou-se em Universidade Federal do Rio de Janeiro (FAVERO, 2006, p. 18; 26-27).

${ }^{7}$ Encontramos notícias sobre sua atuação na Pontifícia Universidade Católica do Rio de Janeiro (PUC/RJ) em 1950 e 1951; na Universidade do Estado do Rio de Janeiro (UERJ) em 1956, onde recebeu a medalha Marechal Hermes como professor da instituição; na Universidade Santa Úrsula (USU); na Faculdade de Serviço Social do Distrito Federal; e na Escola do Comando Maior do Exército (ECEME). Exerceu ainda a presidência da Associação Brasileira das Escolas Normais, na década de 1960, quando promoveu vários eventos, além de presidir o $1^{\circ}$ Congresso Brasileiro de Ensino Normal, realizado no Rio de Janeiro (FRANÇA; DOMINGUES, 2018).

${ }^{8} \mathrm{Na}$ ABE foram registradas as reuniões para discutir o projeto de Lei de Diretrizes e Bases (LDB). Desses encontros, dos quais Fontoura participava na posição de assessor da Comissão de Educação e Cultura da Câmara dos Deputados, o autor elaborou um parecer que, mais à frente, resultou na elaboração do livro "Diretrizes e Bases da Educação Nacional”.
} 
Iniciamos selecionando algumas obras de Fontoura ${ }^{9}$. Observamos de imediato a diversidade de temas, também encontrada em outros autores de manuais pedagógicos ${ }^{10}$, o que demonstra uma formação ampla, geral, comum a esse tipo de autor, que comumente apresenta experiências polivalentes como professor.

Em uma rápida revisão bibliográfica, verificamos que Fontoura é considerado um autor de grande circulação e abrangência por diferentes pesquisadores: [...] Fontoura protagoniza uma grande produção didática que será utilizada por vários anos na formação de professores" (SCHNEIDER; STENTZLER, 2011, p. 9).

Os vários manuais produzidos por Fontoura, acreditamos, fruto de apropriação da literatura científica da época e de suas experiências docentes, "tornaram-se subsidiários das leituras obrigatórias recomendadas para as normalistas e, logo, exerceu notável influência pedagógica no ensino normal maringaense, e foram leituras altamente recomendadas entre as décadas de 50 e 60 do século XX" (VIEIRA; MACIEL, 2012, p.1).

Podemos dizer que apesar de Fontoura ter sido um dos autores mais expressivos no período, divulgando os princípios da Escola Nova em publicações da Editora Aurora, com coleções de manuais destinadas à formação de professores, produzidas em diversas edições e grandes tiragens, e apresentando um discurso que expunha preocupações com a formação dos docentes, há escassez de trabalhos sobre a repercussão de suas práticas metodológicas nos cursos de formação de professores e seu nome é pouco lembrado em teses e dissertações.

O maior destaque que encontramos, sem dúvida, está relacionado à sua atuação intensa na produção de manuais pedagógicos para professores entre os anos de 1940 e 1970. Essa produção foi favorecida pelo surgimento da indústria editorial brasileira, beneficiando a nacionalização dos livros utilizados nas escolas. Desta forma, ao invés da adoção de manuais estrangeiros, como ocorrera por décadas no Brasil, os textos e autores mais referidos são aqueles dos manuais nacionais". E dentre os autores nacionais, cujos manuais tiveram notável circulação, temos Afro do Amaral Fontoura (MACIEL; VIEIRA; SOUZA, 2012, p. 239).

Além da sua atuação como docente e como autor de livros, Fontoura foi escolhido para ser responsável pela Biblioteca Didática Brasileira da Editora Aurora ${ }^{11}$.

Com base nos fatos citados, percebemos uma indicação da expertise de Fontoura nos cursos de formação de professores e sua preocupação em resolver a realização do ideário da Escola Nova em suas obras, enfatizando a operacionalização desse princípio escolanovista. Dessa forma, foi possível verificar seu reconhecimento por sua atuação

9 “Aspectos da Vida Rural Brasileira”, "Dicionário Enciclopédico Brasileiro”, "Didática Geral”, "Didática Especial da Primeira Série”, "Educação Cívica e Calendário Cívico", "Fundamentos da Educação", "Introdução à Sociologia", "Introdução ao Serviço Social”, "Manual de Testes”, "Metodologia do Ensino Primário", "O Drama no Campo", "O Planejamento no Ensino Primário", "O Ruralismo: Base da Economia Nacional”, "Programa de Sociologia", "Prática de Ensino", "Psicologia Geral", "Sociologia Educacional”.

${ }^{10}$ Por "manual pedagógico" compreendem-se impressos como livros, compêndios ou ainda um conjunto de textos reunidos, geralmente organizados por um autor, um grupo de pessoas ou uma instituição. Possui o objetivo de orientar e mediar a prática ou o ofício de ensinar em torno de um saber ou conjunto de saberes, como é o caso dos saberes elementares matemáticos (REPOSITORIO UFSC).

${ }^{11}$ A coleção Biblioteca Didática Brasileira foi organizada por Afro do Amaral Fontoura. Seus autores eram professores das escolas normais, com prestígio entre os futuros docentes, facilitando a implementação de ideias escolanovistas contidas nesta coleção. Foi organizada em duas séries: Série I (A escola viva); Série II (Legislação Brasileira de Educação); (Livros textos para crianças); Série IV como aprender brincando (material didático). (FONTOURA, 1960). Maior aprofundamento ver FRANÇA (2016). 
profissional, bem como pela evidência da sua expertise no campo da educação. Podemos dizer que a circulação e adoção da coleção da Biblioteca Didática Brasileira, possivelmente, foi impulsionada pela necessidade de normatização do ensino no novo Estado da Guanabara. Assim, para dar concretude a essa nova organização, Fontoura foi convocado a se responsabilizar pelas novas diretrizes educacionais. A escolha certamente se deu em função de sua expertise e ampla circulação no campo.

Constituindo nosso corpus documental na primeira etapa, recompilação de experiências docentes, também selecionamos o Programa Mínimo para o ensino primário do Distrito Federal, publicado em 1954, a fim de cotejar com o programa elaborado por Fontoura.

É necessário lembrar que, no período da publicação, a educação era regida pelas orientações da Reforma Capanema ${ }^{12}$.

Um questionamento a ser considerado é: "como concretizar estas mudanças prescritas por Lei?”. Encontramos no Centro de Memória da Educação Brasileira (CMEB) uma publicação de 1954 do Programa Mínimo para o Ensino Primário do Distrito Federal, promulgado em 1952.

Figura 1: capa do Programa Mínimo para o Ensino Primário, 1954.

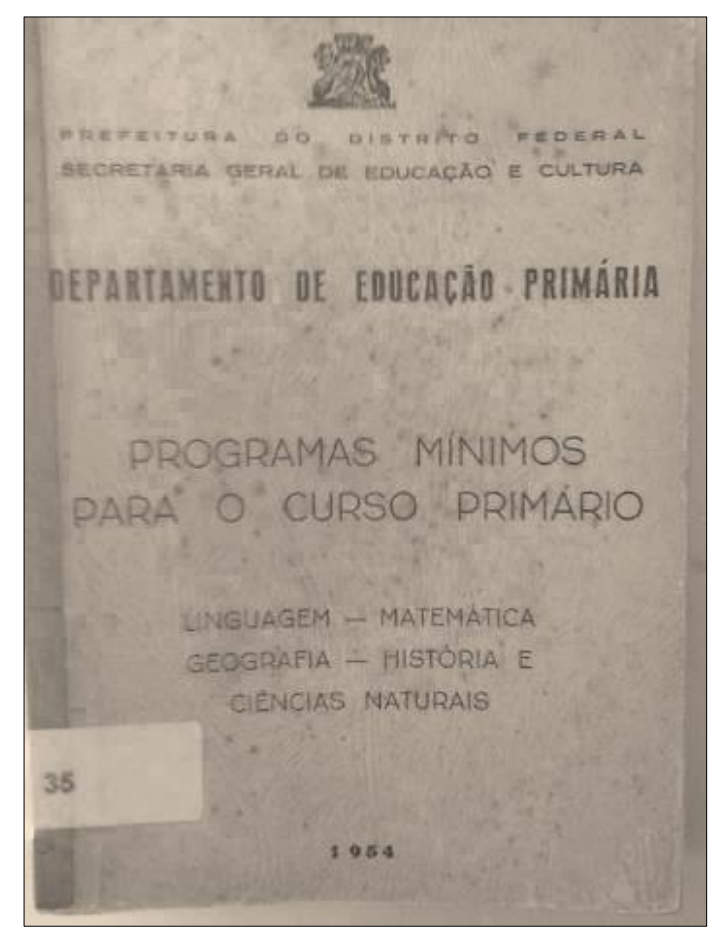

Fonte: CMEB.

Com o documento em mãos, observamos que o Programa de Matemática foi elaborado por Irene de Albuquerque ${ }^{13}$. Nele há a sistematização dos conteúdos mínimos para o ensino primário. Trata-se de uma tentativa de esclarecer aos professores a nova

\footnotetext{
12 Nome dado às transformações propostas ao sistema educacional brasileiro entre 1942 e 1946, liderada por Capanema: tais decretos-lei ficaram conhecidos como Leis Orgânicas do Ensino. Um destes decretos, o Decretolei n ${ }^{\circ} 8.529$, de 2 de janeiro de 1946, já demonstrava suas influências com as ideias escolanovistas, pois se percebe a preocupação com a formação integral da criança, e não apenas com o ler e escrever e com as orientações didáticometodológicas, preocupações ainda tímidas em relacionar a escola com a vida, aprender pela ação, e levar em conta o desenvolvimento infantil para a organização escolar.

${ }^{13}$ Personagem ativa nos ideais escolanovistas. Foi professora catedrática de Prática de Ensino do Curso Normal do Instituto de Educação do Rio de Janeiro, e de Metodologia dos Cursos de Aperfeiçoamento do INEP; autora de manuais didáticos direcionados a futuros professores. (Ver FRANÇA, VILLELA, 2015).
} 
perspectiva de educação. Muitas vezes, insinua a necessidade de novas práticas. Não chega a detalhar, mas oferece orientações gerais quanto à metodologia, talvez por objetivar estabelecer um currículo mínimo.

Para alcançar tal escôpo (sic), seguem-se algumas sugestões de ordem geral.[...] Unificar os processos de cálculo, evitando que o aluno tenha que sofrer constantes reajustamentos ao mudar de professor. Adotar em cada caso os processos mais eficientes, mais intuitivos, mais econômicos ou menos sujeito a êrro (sic). [...]Graduar as dificuldades, ensinar um pouco de cada vez. [...] Prover suficiente fixação da aprendizagem por meio de jogos variados, fazendo preceder cada exercício de uma recapitulação oral do conhecimento a fixar (DISTRITO FEDERAL, 1954, p. 59).

Cabe aqui fazer uma observação quanto ao fato de que a análise realizada não detectou essa representação na matemática para ensinar. Ao que parece, as marcas do Programa ficaram por conta do viés do desenvolvimento infantil e da adequação aos interesses das crianças, assim como da introdução ou distribuição dos conteúdos mínimos entre as séries.

Vale destacar que apesar de a elaboradora do Programa ter sido uma das grandes autoras de manuais didáticos, divulgando novas metodologias para a aritmética, nas propostas do Programa agiu de forma reservada. Não há ênfase nas sugestões de atividades utilizando jogos e materiais como suporte. Podemos inferir que a autora preferiu não trazer as sugestões para o Programa, embora essas atividades já fossem conhecidas pelos professores por meio dos manuais didáticos da época. Talvez esse posicionamento mais neutro tenha se dado para evitar debates desgastantes que prejudicassem a implementação do Programa, ou ainda que dificultassem a continuidade do diálogo e parceria com os professores. Nesse sentido, a autora, possivelmente, resolveu não tomar posições muito radicais, optando por não prescrever a forma de concretizar as ideias escolanovistas em sala de aula.

No entanto, havia necessidade de orientações metodológicas oficiais aos professores. Como fazer a abordagem da matemática e ensinar no método ativo ${ }^{14}$ ? Ou seja, qual matemática para ensinar? Como articular a matemática para ensinar e $a$ ensinar em situações práticas? Isto é, dar conta da educação partindo dos interesses da criança e apoiando-se em suas ações e no seu desenvolvimento. Como fazer isso iniciando pela observação, reflexão e experimentação, respeitando-se o indivíduo e buscando uma melhoria na própria ação? Pensamos que Fontoura, em seus manuais, já vinha ensaiando a sistematização da matemática para ensinar nesta perspectiva.

Assim, podemos inferir, ao final de nossa primeira etapa, que nos materiais estudados há consensos. Contudo, o Programa elaborado por Fontoura apresentava orientações explícitas aos professores, como veremos a seguir.

14 Conforme Souza (2009, p. 189) “[...] os alunos são levados a aprender observando, pesquisando, perguntando, trabalhando, construindo, pensando e resolvendo situações problemáticas que lhes sejam apresentadas, quer em relação a um ambiente de coisas, de objetos e ações práticas, quer em situações de sentido social e moral, mediante ações simbólicas.”. 


\section{Os saberes sistematizados: a matemática $a$ ensinar e a matemática para ensinar no Programa do Ensino Primário do Estado da Guanabara}

A partir das considerações elaboradas sobre matemática $a$ ensinar e matemática para ensinar ${ }^{15}$, aproveitamos para retomar a proposta de investigação sobre esses saberes sistematizados por Amaral Fontoura no Programa da Guanabara, de 1962.

Nesse sentido, retomamos questionamentos, como: quais saberes foram sistematizados por Fontoura no Programa de Aritmética do Estado da Guanabara em $1962^{16}$ ?; que novos saberes oficialmente são estes, instituídos a partir das ações desse personagem?; é possível fazer um contraponto entre esses saberes e aqueles que circulavam anteriormente?; que nova matemática para ensinar, contida no Programa, foi sistematizada para formar professores?

Lembrando que na primeira etapa do processo, em que observamos as transformações de conhecimento em saber, denominada recompilação das experiências docentes, coletamos as orientações dadas ao professor nos manuais produzidos por Fontoura e em outros materiais, como dito anteriormente, produzindo nosso corpus documental.

Em seguida, na análise comparativa dos conhecimentos dos docentes com o nosso corpus documental selecionado, o qual envolve produções de Fontoura, como a Biblioteca Didática Brasileira, da Editora Aurora; a Biblioteca da Professora Primária; a Biblioteca do Professor; o Programa Mínimo (1954), entre outros que tratam do ensino nos primeiros anos escolares, destinando-se a orientar docentes, procuramos caracterizar semelhanças. Assim, buscamos verificar se esses conhecimentos traziam informações convergentes aos docentes, assim como se as orientações propostas coadunavam.

A análise comparativa dos conhecimentos dos docentes visa promover uma nova seleção no âmbito do inventário elaborado anteriormente, com a montagem da coleção de conhecimentos dispersos num dado tempo da história da educação escolar. Tal seleção envolve um novo inventário, agora composto pela separação daquelas informações sobre experiências docentes que se mostram convergentes do ponto de vista da orientação para o trabalho do professor. Por este procedimento de pesquisa tem-se a possibilidade de que sejam reveladas tendências de assentamento de propostas e construção de consensos pedagógicos sobre o que deve o professor saber para a realização de seu ofício. (VALENTE, 2018, p. 381).

Para o último procedimento de sistematização e análise do uso dos conhecimentos como saberes, procuramos analisar o Programa da Guanabara, cotejando com as obras de Fontoura e o Programa Mínimo (1954) anterior, na perspectiva da formação dos saberes profissionais, e problematizando sobre quais saberes foram sistematizados e objetivados por Fontoura por meio do Programa de Aritmética do Estado da Guanabara. O objetivo é verificar quais transformações houve na matemática $a$ ensinar e na matemática para ensinar, comparando o que havia oficialmente e o que foi sistematizado por Fontoura no Programa da Guanabara.

\footnotetext{
15 Seguindo a mesma ideia, a matemática a ensinar está "mais diretamente ligada ao campo disciplinar, à matemática", e a matemática para ensinar está "articulada à profissão docente." (BERTINI; MORAIS; VALENTE, 2017, p. 9).

16 Para a análise, utilizamos a 6 edição do Programa de Estado da Guanabara, de 1965.
} 
O procedimento de sistematização e análise do uso dos conhecimentos como saberes representa a última etapa do percurso que transforma informações sobre experiências docentes em saber profissional do professor. Sistematização e análise de uso são procedimentos realizados concomitantemente. Assim, cabe ao pesquisador ou grupo de pesquisadores, organizar a partir da etapa anterior, uma assepsia de elementos subjetivos e conjunturais dos consensos pedagógicos, de modo a que os conhecimentos possam ser vistos com caráter passível de generalização e de uso, isto é, como saber. De outra parte, a análise inclui, de modo conjunto, a verificação em instâncias normativas e/ou didático-pedagógicas da ocorrência de uso dos elementos sistematizados pelo pesquisador (VALENTE, 2018, p. 381).

Como mencionado anteriormente, o Programa é uma reedição da coleção Biblioteca Didática Brasileira; por esse motivo é interessante confrontar o Programa com as obras de Fontoura que orientam sobre o ensino de matemática. Assim, coletamos as orientações para os professores nos volumes desta coleção, no Programa anterior e em outros manuais de Fontoura.

Para esse primeiro Programa, Fontoura optou por reeditar um manual pedagógico muito popular entre os professores primários da época - O Programa do Ensino Primário do Estado da Guanabara -, que já se tratava da reedição do Programa do Ensino Primário, Volume I, Série II - Legislação do ensino e texto auxiliares (1962), da coleção Biblioteca Didática Brasileira, organizada por ele.

$\mathrm{Na}$ introdução do Programa, Fontoura anuncia a implantação da Escola Renovada da Guanabara, de acordo com as normativas impostas pela LDB n 4.024/1961 e com os avanços da pedagogia e psicologia.

O Estado da Guanabara está de parabéns com a revolução que ora se inicia em seu ensino primário. Revolução pacífica e construtiva destinada a colocar a educação da ex-capital da República em dia com as Ciências Pedagógicas. Com efeito, há nada menos de 50 anos ou 60 anos os grandes mestres da Pedagogia vêm demonstrando o absurdo de se querer exigir de todos os alunos os mesmos resultados (GB, 1965, p. 13).

Figura 2 - Capa e contracapa do Programa para o Curso Primário do Estado da Guanabara (1965).
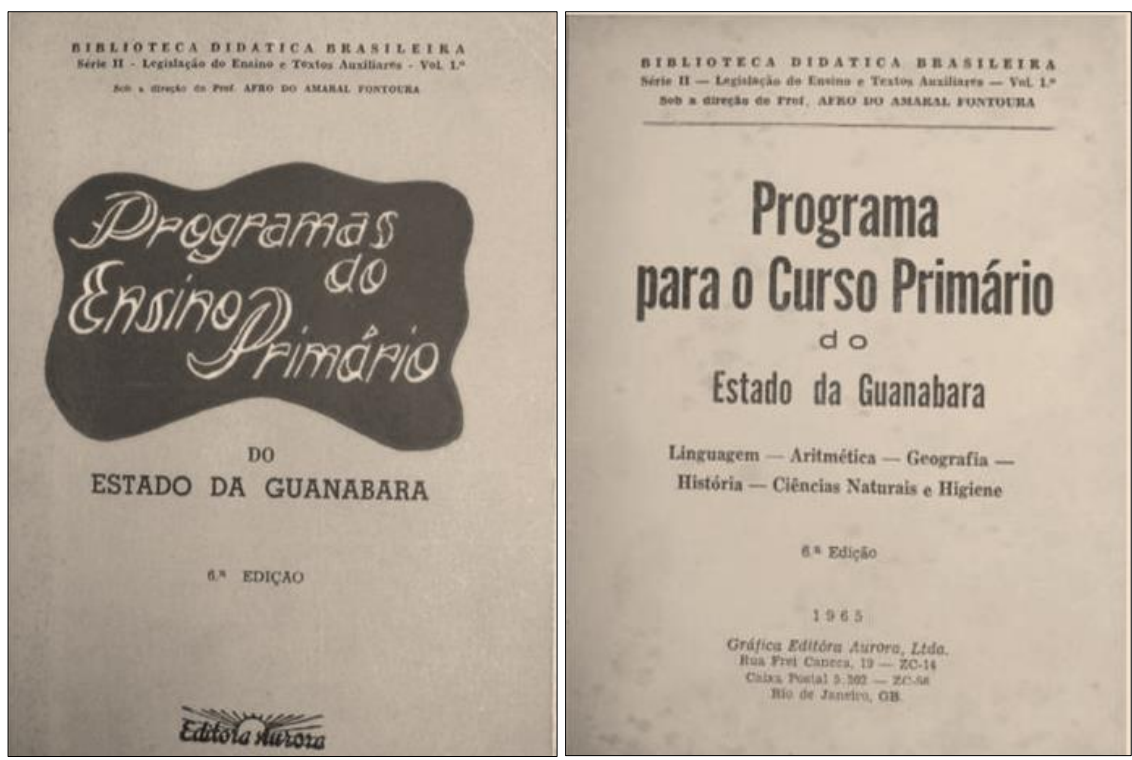

Fonte: Repositório UFSC. 
Para a edição do Programa, acrescentou-se uma introdução escrita por Fontoura, um quadro organizacional elucidando a nova distribuição do curso primário, com seis anos de escolaridade, distribuído em seis séries. A $1^{a}$ série era destinada aos alunos analfabetos, de modo que os alfabetizados já eram alocados na $2^{\mathrm{a}}$ série. Os objetivos gerais vinham acompanhados de sugestões de atividades para Linguagem, Aritmética, Geografia, História, Ciências Naturais e Higiene.

Logo na introdução há indícios da sistematização de um saber organizacional, talvez resultante da influência da psicologia científica, já sistematizada por Fontoura no Manual de Testes ${ }^{17}$, de 1960 , que reflete o período de entrada dos testes pedagógicos e psicológicos na escola. É composto de uma primeira parte, que trata sobre a teoria da Escola Nova, e de outras, encarregadas de prescrever atividades e orientar para a prática do professor. Em outro segmento do Programa, o autor traz explicações teóricas sobre os testes e, posteriormente, apresenta prescrições metodológicas para a sua aplicação. Além disso, indica maneiras de como classificar os alunos a partir dos parâmetros produzidos (FRANÇA, 2016). Nesse Manual, Fontoura (1960, p. 3) argumenta: "Cremos que, igualmente, em todos os estados brasileiros, a verificação do aproveitamento dos milhões de alunos de escolas primárias é feita através de testes", anunciando a necessidade de aplicação desse tipo de instrumento, pois o entende como indispensável à avaliação da aprendizagem, por sua praticidade e objetividade.

Fontoura reproduz essas ideias na introdução do Programa quando justifica a nova estrutura de séries e classes. Podemos dizer que o Programa sistematizou e objetivou saberes relativos ao planejamento, à avaliação, aos métodos e às técnicas referentes à organização interna da sala de aula.

Figura 3: classificação de alunos por série.

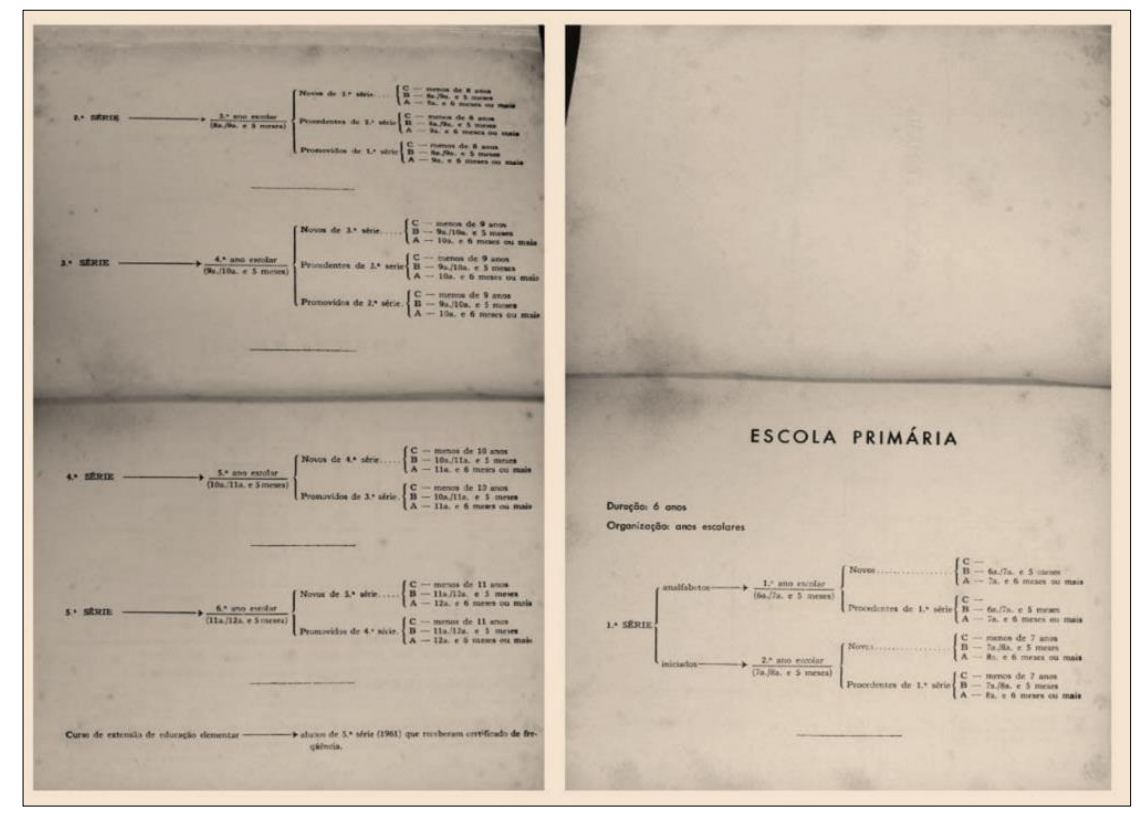

Fonte: Programa do Curso Primário da Guanabara (1962).

\footnotetext{
${ }^{17}$ Ver FRANÇA (2016).
} 
Em seu manual, Metodologia do Ensino Primário ${ }^{18}$, Fontoura, após a introdução, que discorre sobre a teoria da Escola Nova, inicia uma seção em que aparecem prescrições de atividades e orientações para a prática do docente, estruturadas em capítulos que se dividem conforme tópicos a seguir: Programa de Linguagem, Programa de Matemática, Programa de História, de Geografia, Programa de Ciências e Higiene. Cabe destacar, que cada um vem acompanhado de objetivos gerais, orientações metodológicas, mínimo de saberes que cada aluno deveria possuir ao final de cada série e exemplos de atividades didáticas por conteúdo.

O Programa de Matemática Fontoura estrutura suas recomendações apresentando: I - objetivos gerais; II - orientações metodológicas; III - resolução de problemas; IV mínimo que deve ser obtido pelos alunos em cada uma das seis séries. Em seguida, inicia outra sessão por série, com os seguintes títulos: mínimo de conhecimentos e de habilidades a adquirir; exemplificação e sugestões didáticas; noções gerais; conceitos e abordagens distribuídos por série.

Figura 4: Exemplo de classificação dos alunos.

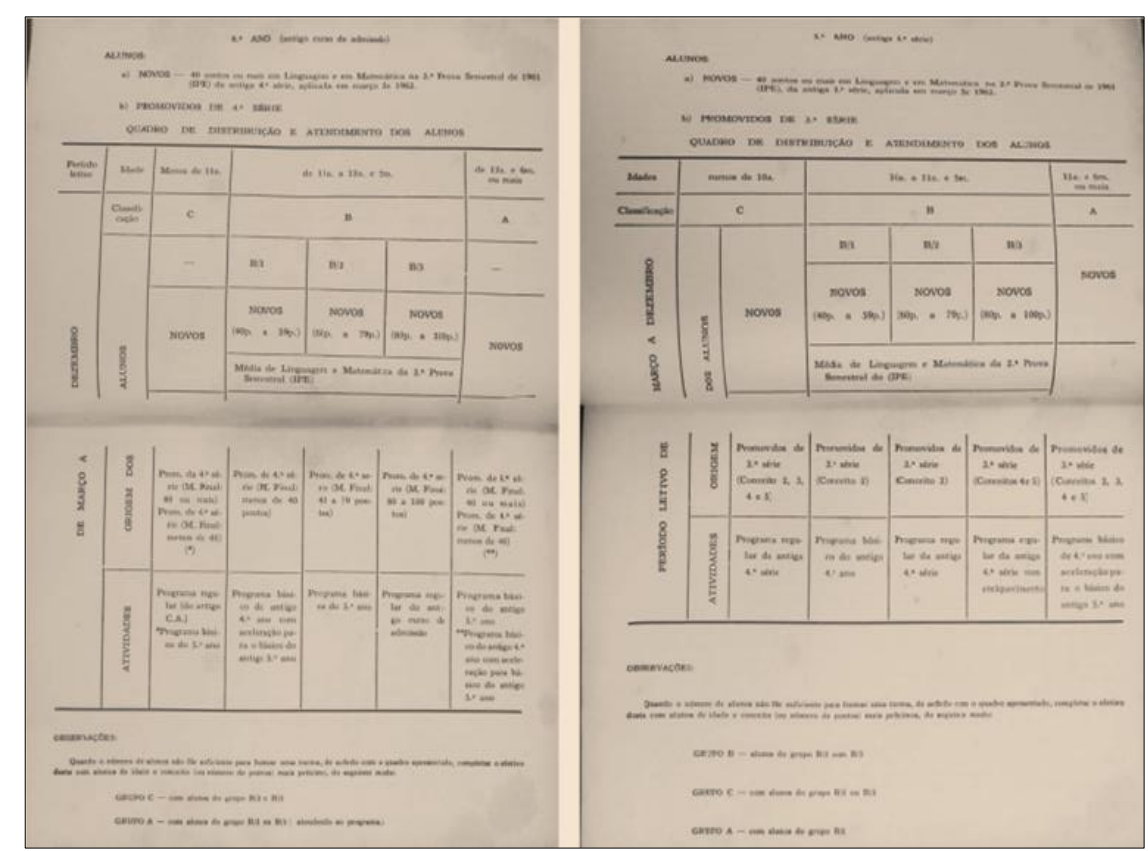

Fonte: Programa do ensino primário do estado da Guanabara (1962).

Nas orientações metodológicas do Programa do Ensino Primário do Estado da Guanabara (1962) fica compreensível sua fundamentação no ideário escolanovista:

Atendendo aos objetivos expostos, o ensino de matemática deverá ser essencialmente prático, graduado, utilitário e agradável. É mister eliminar todos os conhecimentos sem aplicação real, os quais sobrecarregariam inutilmente o trabalho escolar, com prejuízo de sua eficiência. Por outro lado, necessário se torna obter o domínio perfeito dos conhecimentos e habilidades utilizáveis (1962, p. 98).

18 Possui 449 páginas, com dimensões $180 \mathrm{~mm}$ por $135 \mathrm{~mm}$. O manual é subdividido em cinco partes: Metodologia da Linguagem, Metodologia da Matemática, Metodologia das Ciências Sociais, Metodologia das Ciências Naturais e Metodologia do Desenho e dos Trabalhos Manuais. Distribuição diferente do Programa da Guanabara. (FRANÇA, 2016). 
Quadro 1: Síntese do Programa do Ensino Primário (Aritmética) de 1965.

\begin{tabular}{|c|c|}
\hline ANO & ASSUNTOS TRATADOS \\
\hline $\begin{array}{c}1^{\circ} \text { ano escolar } \\
\text { (alunos novos } \\
\text { analfabetos) }\end{array}$ & Alfabetização e contagem. \\
\hline $\begin{array}{l}2^{\mathrm{o}} \text { ano escolar } \\
\left(\text { antiga } 1^{\mathrm{a}} \text { série) }\right.\end{array}$ & $\begin{array}{c}\text { Relativamente a conhecimentos e habilidades. Exemplificação e sugestões } \\
\text { didáticas. Noções gerais (direita, esquerda, grande, pequeno, comparação de } \\
\text { objetos). Prioridade na ideia de contagem; agrupamentos em dezenas as } \\
\text { operações de adição e subtração elementares abordadas concomitantemente, } \\
\text { com resultados até } 99 \text {. Noção do zero como ausência, abordado } \\
\text { posteriormente, quando é explorado o conceito de dezena. Resolução de } \\
\text { problemas relacionados com a vida prática. Sistema legal de unidades de } \\
\text { medir (calendário e hora). Cálculo mental. }\end{array}$ \\
\hline $\begin{array}{l}3^{\mathrm{o}} \text { ano escolar } \\
\text { (antiga } 2^{\mathrm{a}} \text { série) }\end{array}$ & $\begin{array}{c}\text { Revisão dos conhecimentos anteriores de contagem; generalização das } \\
\text { noções de pares e ímpares; contagem até 1000. Técnicas de cálculo mental; } \\
\text { adição até } 3 \text { parcelas e subtração como operação inversa; multiplicação } \\
\text { como soma abreviada (produto até 9000); ideia objetiva da divisão } \\
\text { (quociente até 9). Generalização da noção de fração. Leitura e escrita de } \\
\text { frações com denominadores } 2,3,4,5,6,7,8,9 \text {. Diferentes tipos de } \\
\text { sequências. Sistema monetário. Sistema legal de unidades de medir. } \\
\text { Geometria (sólidos). }\end{array}$ \\
\hline $\begin{array}{l}4^{\mathrm{o}} \text { ano escolar (antiga } \\
3^{\mathrm{a}} \text { série) }\end{array}$ & $\begin{array}{l}\text { Revisão geral. Contagem até o milhão. Multiplicação por multiplicador até } \\
3 \text { algarismos. Divisão com processo longo com divisor até } 2 \text { algarismos. } \\
\text { Fração e número misto. Adição e subtração de frações. Operações com } \\
\text { decimais. Prismas e pirâmides. Figuras geométricas simples. Sistema legal } \\
\text { de unidades de medir. Noção de perímetro. Cálculo mental. }\end{array}$ \\
\hline $\begin{array}{c}5^{\circ} \text { ano escolar (antiga } \\
4^{\mathrm{a}} \text { série) }\end{array}$ & $\begin{array}{l}\text { Revisão geral. Contagem até unidade de bilhões. Cálculo mental de } \\
\text { pequenas expressões numéricas. Operações com números inteiros e suas } \\
\text { propriedades. Operações com frações e números decimais. Porcentagem. } \\
\text { Sistema monetário e transações comerciais utilizando cálculo mental. } \\
\text { Cálculo de área. }\end{array}$ \\
\hline $\begin{array}{l}\text { Curso de admissão } \\
\text { (antigo } 6^{\circ} \text { ano } \\
\text { escolar) }\end{array}$ & $\begin{array}{l}\text { Revisão geral de todos os conteúdos dos anos anteriores com } \\
\text { aprofundamento. Cálculo mental. }\end{array}$ \\
\hline
\end{tabular}

Fonte: Resumo elaborado pelos autores a partir do Programa (1965).

Há algumas particularidades neste Programa. A primeira delas é a sistematização do cálculo mental desde o $2^{\circ}$ ano de escolaridade, inclusive utilizado em geometria e sistema monetário (ver Programa do Ensino Primário do Estado da Guanabara, 1962). Vejamos alguns exemplos: O cálculo mental deve ser empregado em problemas aplicando apenas uma das noções de cada vez (p. 115); cálculo mental de dezenas e dúzias (p. 115); cálculo mental preparatório para a multiplicação com reserva (p. 121); cálculo mental preparatório para a divisão (p. 122); cálculo mental com Cruzeiros (p. 125). Para $3^{\circ}$ ano: cálculo mental da adição aliado a multiplicação (p. 128); concurso de cálculo escrito e oral (p. 137). Para o $4^{\circ}$ ano: cálculo mental envolvendo quantias (p. 135); cálculo mental envolvendo expressões simples necessárias para a aprendizagem do processo abreviado de divisão (p. 138); cálculo mental 
envolvendo transações comerciais (p. 145). Para o $5^{\circ}$ ano: cálculo mental de perímetros e áreas (p. 146). Este fato fica comprovado se observarmos os objetivos do Programa de Matemática:

Resolver, com exatidão e presteza, problemas da vida prática; desenvolver bons métodos de pensamento usando da melhor forma seus recursos mentais; dar resposta imediata e correta a todas as operações elementares; [...] usar o conceito de cálculo mental para resolução de problemas práticos, com rapidez e segurança (GB, 1965, p. 98).

Em relação à descrição dos conceitos a serem abordados em cada série, esses, elencados acima, são apresentados de maneira detalhada com exemplos de abordagem e orientações para professores em cada matéria. Há diálogo com o professor apresentando recomendações sobre o enfoque que deveria ser aplicado.

O método ativo era evidenciado a partir de exercícios práticos, do desenvolvimento do raciocínio e da utilização de materiais, inclusive com o uso de diferentes jogos. Em relação a esses aspectos, Fontoura orienta o uso de concursos semanais de cálculo para desenvolver técnicas de cálculo mental:

Organizar semanalmente, para estimular a exatidão e rapidez, concurso de cálculo (duração de 5 a 20 minutos, conforme a série) de acordo com o nível da classe, com tempo marcado (sempre o mesmo), e domínio apenas de uma dificuldade de cada operação (exemplo: multiplicação propor multiplicador de um algarismo com reservas). (GB, 1965, p.101).

Podemos inferir que um saber relacionado a matemática para ensinar, no caso, a utilização de jogos e concursos de cálculo, foi sistematizado no Programa, e coaduna ao protagonismo dado aos alunos nas tarefas que preconizavam projetos e centros de interesses ${ }^{19}$ que estão diretamente relacionados com a chamada Escola Ativa, defendida pelo Escolanovismo. Fontoura fornecia as seguintes orientações sobre a matemática para ensinar:

Motivação - a) partir do concreto; b) não dar dados absurdos; c) partir da experiência da criança; d) partir das atividades infantis na escola; e) partir sempre que possível de um projeto; f) estabelecer pesquisas (FONTOURA, 1961, p. 209-210).

Verificamos também que os exemplos contidos no Programa tinham enunciados curtos e respostas objetivas. Percebe-se que o material enfatizava aspectos como o tempo utilizado na execução das atividades, a sistematização do ensino e padronização, e os conceitos que estavam mergulhados na representação da vaga pedagógica adotada pelo autor.

A circulação dos manuais de Fontoura no Instituto de Educação pode ser certificada pelo registro de compras da Biblioteca do Curso de Formação de Professores para Ensino Normal (CFPEN) e da Biblioteca Histórica do Instituto de Educação, a que tivemos acesso nos acervos do CMEB. O exercício de pesquisa arquivista proporcionou a constatação de que esses manuais foram adquiridos pela instituição em grande quantidade, de modo que os exemplares ficavam disponíveis na Biblioteca do Professor, onde pude observar, por meio de consultas ao

\footnotetext{
${ }^{19}$ Em terras brasileiras, Lourenço Filho e Abner de Moura foram os divulgadores da proposta de Ovide Decroly de que o ensino deveria partir dos centros de interesses. O livro de Abner de Moura, de 1931, Os Centros de Interesse na Escola: sugestões para lições globalizadas segundo o sistema Decroly, teve prefácio de Lourenço Filho e compunha a Biblioteca da Educação (CAMARGO, 2000, p. 111).
} 
seu livro de registro ${ }^{20}$, que o material obtinha um grande número de acesso. No que concerne à quantidade de exemplares presentes na biblioteca do Instituto, cabe ressaltar que isso evidencia o fato de os professores compreenderem os saberes matemáticos presentes no material produzido por Fontoura como elementares.

Assim, de acordo com nossa pesquisa, sua produção foi extensa, sobretudo de manuais pedagógicos. Publicou uma cartilha, quatro compilações de legislação educacional e dezenove manuais.

\section{Algumas considerações}

Valente (2018, p. 384) destaca que as pesquisas que estudam a construção histórica dos saberes profissionais podem subsidiar os projetos futuros de formação de professores e, assim, auxiliar a diminuir a distância entre o ambiente de formação do futuro professor e o lugar onde exercerá seu ofício.

Dessa forma, esta pesquisa se localiza nesse cenário, procurando caracterizar os saberes necessários a um professor que ensina Matemática com base no Programa do Ensino Primário do Estado da Guanabara.

As análises até aqui apresentadas tornam possível a sistematização de resultados que respondem as seguintes questões: que vestígios nos possibilitam afirmar que Afro do Amaral Fontoura foi um expert para o curso de formação de professores que ensinava matemática nas séries iniciais no período de 1950 a 1970, com ideias escolanovistas? Que saberes foram sistematizados e objetivados por Fontoura por meio do Programa de Aritmética do Estado da Guanabara?

Antes de tudo, importa destacar que a sistematização de saberes esteve em voga nos processos de profissionalização da formação do professor ao longo do período analisado. No Programa estudado, optamos por destacar alguns saberes $a$ ensinar e para ensinar objetivados por Fontoura. Dentre os saberes a ensinar, enfocamos o aritmético, especificamente o cálculo mental. Quanto aos saberes para ensinar, priorizamos a metodologia de jogos e saberes profissionais referentes à organização de sala de aula.

De acordo com França (2016), Fontoura ficou responsável por produzir o Programa de Aritmética de 1962 do Estado da Guanabara. Isso evidencia que o docente exerceu uma função estatal atuando na produção de um Programa para o novo Estado da Guanabara. Fontoura tinha reconhecimento de seus pares e conhecimento sobre a profissão docente, uma vez que atuou na formação de professores primários do Instituto de Educação, além de ter sido também professor de instituições de nível superior, como Puc-Rio, Uerj, USU, Eceme e, ainda, ter ocupado o cargo de presidente da Associação Brasileira das Escolas Normais. Tais fatos evidenciam ainda mais a sua expertise.

Além disso, não podemos deixar de lado a apropriação da literatura científica da época, sistematizada quantitativamente pelo autor. Sobre esse aspecto, destacamos a sua polivalência, uma vez que teve publicações em diferentes áreas, caracterizando a produção e sistematização de saberes.

A circulação dos conhecimentos produzidos por Fontoura é verificada a partir da documentação do Instituto de Educação. Apesar disso, há também outros fatores que contribuíram para que essa circulação fosse efetiva, dentre elas: os autores dos manuais da época, em sua grande maioria, eram professores de escolas normais e gozavam de prestígio entre os futuros docentes; o número expressivo de edições atingido pela coleção organizada por Fontoura, facilitando a aceitação das propostas reformistas; e a posição de poder ocupada por Fontoura, no momento das reformas do Estado da Guanabara.

\footnotetext{
${ }^{20}$ Material pertencente ao acervo do Centro de Memória do ISERJ, ainda não disponibilizado virtualmente.
} 
Podemos explicar o surgimento de uma nova matemática para ensinar Aritmética, e a inclusão e exclusão de conteúdos na matemática $a$ ensinar? Com relação aos saberes matemáticos elementares para ensinar, analisados na obra de Fontoura, o autor acompanha o ideário da Escola Nova em relação aos métodos de ensino. Nesse sentido, observamos estreitas relações entre a psicologia e a pedagogia, condicionando as atividades ao desenvolvimento das potencialidades dos alunos, com uso de diferentes recursos materiais em sala de aula como forma de auxiliar o aluno em sua aprendizagem.

Podemos ainda tentar entender as mudanças na matemática para ensinar, presentes no Programa, se considerarmos que as produções de Fontoura, de modo geral, tinham como centralidade orientar as ações do professor em sala de aula, um saber prescrito e instrumental. Assim, Fontoura reproduziu no Programa saberes para a formação de professores que defendia em suas obras; saberes que corroboravam com os ideais escolanovistas, tais como: relacionar a escola com a vida, aprender pela ação e levar em conta o desenvolvimento infantil para a organização das aprendizagens na escola. Para esse movimento, a ênfase da educação não está na acumulação de conhecimentos, mas na capacidade de aplicá-los às situações vividas.

Em síntese, o estudo acerca dessas questões aponta um saber objetivado por Fontoura na elaboração de orientações para ensinar Aritmética na escola primária em tempos da Escola Nova no Brasil, influenciando na formação de professores desse segmento no período referenciado. Reforçamos que sua trajetória profissional pode ter colaborado na circulação de suas ideias sobre a matemática para ensinar.

Desse modo, a partir das características estabelecidas ao longo do estudo, verificamos que Fontoura se enquadra na categoria de expert da matemática escolar em tempos da Escola Nova. Sobre esse aspecto, o autor preenche os seguintes requisitos: formação sólida resultante de seus estudos e práticas da profissão; elaboração de saberes que foram objetivados no Programa do Ensino Primário do Estado da Guanabara; grande circulação de suas propostas em manuais pedagógicos e textos que influenciaram uma geração de educadores, tendo protagonizado ações que permearam a elaboração de políticas relacionadas à formação de professores.

No que diz respeito à matemática $a$ ensinar, alguns conteúdos parecem ter ganhado mais destaque. São eles: a construção do conceito de número, o ensino das quatro operações, o ensino de frações, tabuada e os problemas. O Programa enfatizava como elementar as quatro operações, os cálculos rápidos e o cálculo mental, ou seja, uma Aritmética prática. Interessante também considerar a preocupação com a exploração do sistema monetário e suas transações, visto que tinha por objetivo atender a uma mão de obra principalmente voltada ao comércio.

Quanto à matemática para ensinar, concluímos que os saberes objetivados no Programa, acompanharam as recomendações dos campos da psicologia e da didática em relação à preocupação com o que ensinar em cada etapa de escolaridade. Assim, enfatizou-se uma abordagem prática, utilitária, graduada e agradável para a Aritmética, com a utilização de jogos e saberes profissionais referentes à organização de sala de aula.

$\mathrm{O}$ estudo aqui apresentado, de natureza histórica, merece um aprofundamento em relação às obras de Afro do Amaral Fontoura. Na trajetória da pesquisa foi observado que o autor norteou o ensino normal no período de 1930 a 1970 com uma produção bibliográfica muito extensa, o que solicita um olhar em sua direção.

Em suma, Afro Amaral Fontoura, em função de sua expertise, possibilitou a sistematização e objetivação de saberes aritméticos que consideravam situações da vida prática do aluno, além de propostas funcionais, como o cálculo mental, utilitário e rápido em jogos e concursos, e saberes referentes à forma de organização de uma sala de aula, de acordo com os estudos da psicologia científica. 


\section{Referências}

BERTINI, L. F. de; MORAIS, R. S. dos.; VALENTE, W. R. A Matemática a ensinar e a Matemática para ensinar: novos estudos sobre a formação de professores. São Paulo: Editora Livraria da Física, 2017.

BRASIL. Distrito Federal. Decreto - Lei no 8.529, de 2 de janeiro de 1946. Lei Orgânica do Ensino Primário. Disponível em: https://www2.camara.leg.br/legin/fed/declei/1940-1949/decreto-lei8529-2-janeiro-1946-458442-publicacaooriginal-1-pe.html. Acesso em: 6 mar. 2020.

BRASIL. Distrito Federal. Programa 1954. Disponível em: https://www2.camara.leg.br/ legin/fed/declei/1940-1949/decreto-lei-8529-2-janeiro-1946-458442-publicacaooriginal-1-pe. html. Acesso em: 6 mar. 2020.

BRASIL. Lei de Diretrizes e Bases da Educação. Rio de Janeiro, 23 de julho de 1960. Disponível em: http://memoria.bn.br/docreader/093718_04/4732. Acesso em: 30 jul. 2019.

CAMARGO, M. A. J. G. Coisas velhas: um percurso de investigação sobre cultura escolar (1928 - 1958). São Paulo: Editora UNESP. 2000.

CURSO para professores começam amanhã. O FLUMINENSE, Rio de Janeiro, 1964. Disponível em: http://memoria.bn.br/DocReader/100439_10/11437. Acesso em: 30 de jul. 2019.

CURSO para professores do ensino supletivos. Diário de Notícias, Rio de Janeiro, 22 de julho de 1960. Disponível em: http://memoria.bn.br/DocReader/093718_04/5552. Acesso: 30 jul. 2019.

FAVERO, M. L.A. de. A universidade no Brasil: das origens à Reforma Universitária de 1968. Educ. rev., Curitiba, n.28, p.17-36, dez. 2006. Disponível em: http://www.scielo.br/ scielo.php?script=sci_arttext\&pid=S0104-40602006000200003\&lng=pt\&nrm=iso. Acesso em: 14 ago. 2019. DOI: https://doi.org/10.1590/S0104-40602006000200003

FONTOURA, A. A. do. Manual de testes. Rio de Janeiro: Editora Aurora, 1960a.

FONTOURA, A. A. do. Prática de Ensino. Rio de Janeiro: Editora Aurora, 1960b.

FONTOURA, A. A. do. Metodologia do ensino primário. Rio de Janeiro: Editora Aurora, 1961.

FONTOURA, A. A. do. Programa para o Curso Primário do estado da Guanabara. Série II, Ed. 6. Estado da Guanabara: Editora Aurora, 1965. Disponível em: https://repositorio.ufsc.br/handle/ 123456789/134100. Acesso em: 17 jul. 2019.

FRANÇA, D. M. A. de. Biblioteca didática brasileira: o manual de testes e as propostas escolanovistas em cursos de formação de professores (1950-1970). Rematec - Revista de Matemática, Ensino e Cultura, v. 23, p. 38-51, 2016. Disponível em: http://www.eventos.ufes.br/enaphem/3enaphem/ paper/viewFile/2073/78. Acesso em: 6 ago. 2019.

FRANÇA, D. M. A.; DOMINGUES, J. M. AFRO AMARAL FONTOURA: Um expert para a formação de professores? In: XVI Seminário Temático: Provas, Exames e a escrita da história da educação matemática, 2018, Boa Vista. Anais [...]. Boa Vista: UFRR, 2018. Disponível em: http://xviseminariotematico.paginas.ufsc.br/files/2018/03/FRANCA_DOMINGUES_T3.pdf.

Acesso em 6 ago. 2019. 
FRANÇA, D. M. A.; VILLELA, L. M. A. Notícias do Rio de Janeiro: Aritmética, Geometria e Desenho no Ensino Primário (1890-1970). JIEEM - Jornal Internacional de Estudos em Educação Matemática; IJSME - International Journal for Studies in Mathematics Education. v.8, n.1, p.155-176, 2015. Disponível em: http://revista.pgsskroton.com.br/index.php/jieem/issue/view/42. Acesso em: 15 jun. 2016.

HOFSTETTER, R., SCHNEUWLY, B.; FREYMOND, M. Penetrar na verdade da escola para ter elementos concretos de sua avaliação: a irresistível institucionalização do expert em educação (século XIX e XX). In: HOFSTETTER, R.; VALENTE, W. R. (org.). Saberes em (trans)formação: tema central da formação de professores. São Paulo: Editora Livraria da Física, 2017. p. 55-112.

MACIEL, L.S.B.; VIEIRA, R.A.; SOUZA, F.C.L. Afro do Amaral Fontoura: estudos, produções e a escola viva. Revista HISTEDBR On-line, n.47, p.232-250, set.2012. Disponível em: $\quad$ https://periodicos.sbu.unicamp.br/ojs/index.php/histedbr/article/view/8640049/7608. Acesso em: 6 ago. 2019. DOI: https://doi.org/10.20396/rho.v12i47.8640049

MACIEL, V. M. Elementos do saber profissional do professor que ensina Matemática: uma aritmética para ensinar nos manuais pedagógicos (1880 - 1920). 2019. Tese de doutorado (Doutorado em Ciências). Universidade Federal de São Paulo, São Paulo, 2019.

SCHNEIDER, L. A. D.; STENTZLER, M. M. Prescrições didáticas de Afro do Amaral Fontoura e seu uso na Escola Normal Professora Amasília In: JORNADA DO HISTEDBR, 10. 2011, Vitória da Conquista, BA. Anais [...]. Vitória da Conquista, BA, Jornada do HISTEDBR. 2011. Disponível em: http://www.histedbr.fae.unicamp.br/acer_histedbr/jornada/jornada10/ apresentacao.html. Acesso em: 9 ago. 2019.

SOUZA, R. F. Alicerces da Pátria: História da escola primária no Estado de São Paulo (18901976). Campinas, SP: Mercado de Letras, 2009.

TADEI, G. B. S. da. A psicologia da educação nos manuais didáticos de Afro do Amaral Fontoura (Paraná, 1950-1970). 2016. 319 f. Tese (Doutorado em Educação) - Centro de Ciências Humanas, Letras e Artes, Universidade Estadual de Maringá, Maringá, 2016.

VALENTE, W.R. A Matemática a ensinar e a Matemática para ensinar: os saberes para a formação do educador matemático. In: HOFSTETTER, R.; VALENTE, W. R. (org.). Saberes em (trans)formação: tema central da formação de professores. São Paulo: Editora Livraria da Física, 2017. p.201-228.

VALENTE, W.R. Processos de investigação histórica da constituição do saber profissional do professor que ensina Matemática. Acta Scientiae, v.20, n.3, p.377-385, maio/jun. 2018. DOI: https://doi.org/10.17648/acta.scientiae.v20iss3id3906

VALENTE, W.R. Saber objetivado e formação de professores: reflexões pedagógicoepistemológicas Revista História da Educação (Online), v.23, p.1-22, 2019a. DOI: https://doi.org/10.1590/2236-3459/77747

VIDAL, D. G. Escola nova e processo educativo. In: LOPES, Eliane Marta Teixeira; FARIA FILHO, Luciano Mendes de; VEIGA, Cynthia Greive (orgs.). 500 anos de educação no Brasil. 5 ed. p.497-517. Belo Horizonte: Autêntica Editora, 2011. 